\title{
Citología Testicular mediante Aspiración con Aguja Fina en Perros Adultos y Geriátricos
}

\author{
Testicular Fine Needle Aspiration Cytology in Adults and Geriatric Dogs \\ Alfonso Sánchez R. ${ }^{1,2,3}$, Daniela Díaz T. ${ }^{\text {, Tamara Melo A. }}{ }^{1}$
}

\section{Resumen}

Con el propósito de describir y comparar la citología testicular en perros adultos y geriátricos, se seleccionaron para orquiectomía 10 perros adultos (2-6 años) y 10 geriátricos ( $>8$ años) sin patologías testiculares aparentes. Una vez recolectados los testículos se realizó punción y aspiración con aguja fina (AAF), obteniéndose cuatro muestras por perro. Las muestras fueron teñidas con May-Grünwald Giemsa y estudiadas al microscopio óptico. En la descripción celular se reconocieron los componentes celulares de los túbulos seminíferos e intersticio, así como también células anormales. Destacó la abundancia celular, lisis celular, restos citoplasmáticos y fondos teñidos en la mayoría de las muestras. En ambos grupos se observaron células redondas, multinucleación, núcleos bien teñidos, en ocasiones desnudos y patrón de cromatina condensada. En perros adultos se observó mayor número de células germinales, espermatozoides y totales $(\mathrm{p}<0.05)$ $\mathrm{y}$ en los geriátricos mayor número de células anormales $(\mathrm{p}<0.05$; Chi cuadrado).

Palabras clave: testículos, perro, citología, aspiración con aguja fina

\section{Abstract}

The testicular cytology in adult and geriatric dogs was described and compared between two age groups selected for orchiectomy. Ten adult dogs (2-6 years old) and 10 geriatric dogs ( $>8$ years) without apparent testicular pathologies were studied. Once collected the testes needle aspiration was performed using fine needle (AAF) obtaining four samples per dog. Samples were stained with May-Grunwald Giemsa and examined

\footnotetext{
${ }^{1}$ Facultad de Recursos Naturales y Medicina Veterinaria, Escuela de Medicina Veterinaria, Universidad Santo Tomás, Viña del Mar, Chile

${ }^{2}$ Facultad de Medicina Veterinaria y Agronomía, Escuela de Medicina Veterinaria, Universidad de Las Américas, Viña del Mar, Chile

${ }^{3}$ E-mail: profesanchez@gmail.com
}

Recibido: 16 de enero de 2016

Aceptado para publicación: 22 de abril de 2016 
under the microscope. In the cell description the cellular components of the seminiferous tubules and interstitium, as well as abnormal cells were recognized. The main findings included the cell abundance, cell lysis, debris and cytoplasmic dyed in most samples. In both groups were observed round cells, multi-nucleation, stained nuclei sometimes bare and condensed chromatin pattern. Adult dogs showed higher number of germ cells, sperm and total cells $(\mathrm{p}<0.05)$ and in geriatric was observed greater number of abnormal cells ( $\mathrm{p}<0.05$, Chi-square).

Key words: testis, dog, cytology, fine needle aspiration

\section{INTRODUCCIÓN}

El citodiagnóstico es un tipo de diagnóstico morfológico basado en los caracteres microscópicos de células y componentes extracelulares desprendidos espontáneamente de los tejidos u obtenidos por procedimientos. La aspiración con aguja fina (AAF) es una de las técnicas de recogida de muestra y se considera útil en la práctica clínica como guía en la determinación de múltiples procesos, tanto fisiológicos como patológicos (Raskin y Meyer, 2010). La primera indicación para la AAF testicular y evaluación citológica es el aumento de tamaño testicular, sea unilateral o bilateral. El citodiagnóstico es útil para diferenciar entre condiciones inflamatorias y neoplásicas que pueden ocasionar el agrandamiento testicular, para clasificar las neoplasias y, también, como herramienta para la evaluación de la infertilidad del perro (Masserdotti et al., 2005; Romagnoli et al., 2009).

Las ventajas de la AAF en la clínica reproductiva canina incluyen ser un procedimiento mínimamente invasivo, rápido, de bajo costo y menos doloroso que una biopsia por cirugía (Dahlbom et al., 1997; Santos et al., 2010; Gouletsou et al., 2011); además, puede ser considerada como un procedimiento ambulatorio rutinario (Romagnoli et al., 2009). Una ventaja adicional sería la posibilidad de obtener varias muestras, desde diferentes áreas del testículo, proporcionando muestras más representativas respecto a una biopsia testicular (Santos et al., 2010).
La AAF testicular no se asocia comúnmente con efectos adversos inmediatos o a largo plazo (Root Kustritz, 2006), sin embargo resulta importante considerar que puede ocurrir un leve edema escrotal y eritema dentro de las 72 horas posteriores a la punción y aspiración (James et al., 1979). Gouletsou et al. (2011), estudiando el impacto de la punción y aspiración testicular sobre parámetros clínicos, ultrasonográficos y seminológicos en perros, concluyeron que esta técnica podría ser considerada segura.

Considerando que la casuística reproductiva por trastornos de fertilidad es cada vez más frecuente y que la longevidad de los pacientes caninos se ha visto incrementada, el propósito del presente estudio fue estudiar y describir la citología testicular en perros adultos y geriátricos, y establecer una comparación entre ambos grupos etarios. Asumiendo una relación inversa entre edad y fertilidad (Johnston et al., 2001), se postula la hipótesis de que los recuentos celulares totales y parciales entre ambos grupos deberían presentar diferencias biológicas significativas.

\section{Materiales y Métodos}

\section{Lugar del Estudio}

Se realizaron orquiectomías selectivas a 20 perros con propietarios en el Hospital Clínico Veterinario de la Universidad Santo Tomás de Viña del Mar y en el programa de control de la población canina y felina del 
Departamento de Salud Municipal de la Ilustre Municipalidad de Limache, Chile.

Mediante examen testicular (tamaño, simetría, deslizamiento, tono, sensibilidad y ecografía) se excluyeron del estudio perros con testículos retenidos, evidentemente tumorales y con cualquier signo sugerente de orquitis. Con el fin de estandarizar los pacientes, se consideraron perros entre 10 y 40 $\mathrm{kg}$ de peso. El rango de edad para los perros adultos se estableció entre 2 y 6 años $(n=10)$, y para los perros geriátricos sobre los 8 años $(n=10)$.

\section{Obtención y Procesamiento de las Muestras}

Posterior a la orquiectomía, los testículos se almacenaron en frascos estériles y sumergidos en suero fisiológico para su transporte al laboratorio y realizar la AAF. Todo el proceso de preparación y tinción de las muestras citológicas se llevó a cabo en el laboratorio de patología del Hospital Clínico Veterinario. La técnica de recogida de muestra se realizó con una mariposa de 22-G y una jeringa de $10 \mathrm{ml}$. El área de la punción correspondió al centro del testículo, en el lado opuesto del epidídimo (Gouletsou et al., 2011). Se realizaron dos punciones en dos puntos por testículo. Se aplicó succión constante usando la jeringa. La aguja se dirigió en tres direcciones dentro del testículo con movimientos seguros y rápidos, mientras se mantuvo la succión. Luego, se sujetó la aguja de la mariposa, se liberó la jeringa y se retiró la aguja. Posteriormente, la jeringa se llenó de aire, se conectó nuevamente a la mariposa y el contenido se expulsó en una lámina portaobjetos para realizar un extendido citológico, que fue secado al aire a temperatura ambiente (Gouletsou et al., 2011).

Para la tinción de las muestras se utilizó May-Grünwald Giemsa, siguiendo el método propuesto por Masserdotti et al. (2005) y Romagnoli et al. (2009). Se pegó un cubreobjetos sobre el extendido para observar la muestra con aceite de inmersión (1000x). Cada muestra debía contener al menos 50 células, lo que aseguraría que la muestra sea adecuadamente celular (Masserdotti et al., 2005).

En cada muestra se estudiaron 10 campos al microscopio óptico en los aumentos 40x, 100x, 400x y 1000x, recorriéndolas en orientación zigzag, de derecha a izquierda. En los aumentos 40x y 100x se evaluó la disposición de las células, su organización (aglomeraciones/células aisladas) y coloración del fondo. Bajo aumento de 400x se reconocieron, clasificaron y contabilizaron las células por grupo/categoría celular: número de células de Sertoli, número de células intersticiales o de Leydig, número de células rotas (ruptura de citoplasma/estructuras libres), número de células germinales (incluyen espermatogonias, espermatocitos primarios y secundarios y espermátidas tempranas y tardías), número de espermatozoides, número de células anormales y número de células inflamatorias. Además se describe la presencia de restos citoplasmáticos (abundante/escaso), características del fondo de la muestra (liso/granulaciones) y de núcleos desnudos.

Bajo aumento de 1000x, se realizó la descripción de la forma celular (redonda/ovalada/alargada), tamaño celular (grande/pequeño) y de las siguientes estructuras celulares:

- Citoplasma: cantidad (abundante, escaso), coloración (pálido, leve o moderadamente basófilo), vacuolas (presente, ausente), granulaciones (presente, ausente), bordes (definidos, irregulares).

- Núcleo: forma (redondo, ovalado), tamaño (grande, pequeño), coloración (pobre o densamente teñido).

- Nucléolo: número (único, múltiples), forma (redondo, ovalado), tamaño (grande, pequeño).

- Cromatina: patrón (compacto, acordonado, grueso, delgado, disperso, puntillado, reticular), figuras mitóticas (presente, ausente, frecuente, no frecuente). 

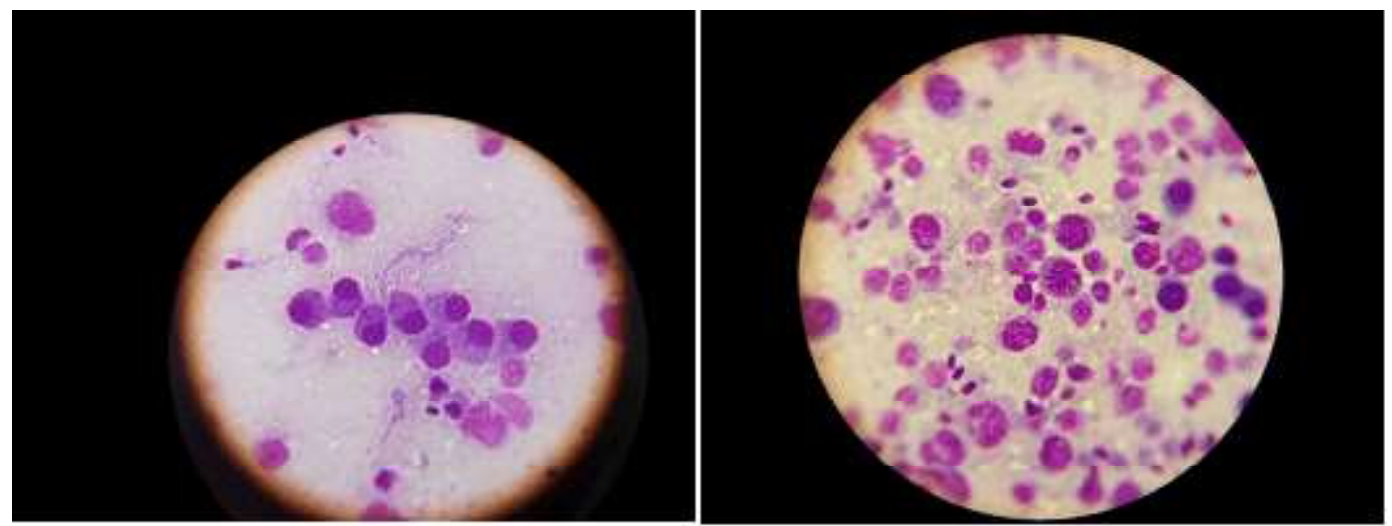

Figura 1. Células testiculares colectadas mediante aspiración con aguja fina. A. Células de Sertoli en el centro de la imagen. B. Espermatocitos primarios en el centro de la imagen. May-Grünwald Giemsa, 1000x

Las células germinales se clasificaron en un mismo grupo, dado que existe mucha similitud entre los diferentes estadios de desarrollo celular y deformación de las células al momento de la aspiración (Raskin y Meyer, 2010).

\section{Análisis Estadístico}

Para establecer la relación entre las variables cualitativas, células del tejido testicular y edad de los perros, se realizó una prueba hipótesis con Chi-cuadrado. Para tal efecto, se confeccionó una tabla de contingencia y con los datos registrados se calculó el porcentaje de células por edad (distribución marginal de la edad) y el porcentaje de células por categoría celular y edad (distribución condicional de la edad). Los valores de la tabla de contingencia se ingresaron al programa estadístico Winstats estableciéndose un valor de $\mathrm{p}<0.05$ para determinar la significancia (Suárez, 2012).

\section{Resultados y Discusión}

\section{Citología Testicular}

Bajo aumento de 40x se observaron mayormente campos con alta cantidad de células, en ocasiones con aglomeraciones, pero en general con una distribución uniforme. Los fondos de las muestras se observaron teñidos en tonos levemente basófilos.

Bajo aumento de 100x se observó la forma redonda de los distintos tipos celulares con núcleos bien teñidos. Los restos citoplasmáticos, así como las células rotas, se hicieron más visibles. En todos los campos se observó lisis celular. También se apreció claramente la disposición en grupo de las células de Sertoli entre las células germinales.

Bajo aumento de 400x fueron más evidentes las agrupaciones de las células de Sertoli con las células germinales, especialmente con los espermatocitos primarios. Los espermatozoides se observaron en agrupaciones de 5 a 20 células. Las espermátidas tardías estaban bastante teñidas (basófilas). Las células de Leydig se encontraban en poca cantidad y generalmente aisladas con nucléolos pequeños.

Bajo aumento de 1000x fue posible distinguir claramente la forma redonda de las células germinales y de los núcleos de las células de Sertoli (Figura 1A), las formas ovaladas de las células de Leydig y las formas alargadas de las espermátidas tardías. Las células de Sertoli se observaron de mayor tamaño que las espermátidas y células 
Cuadro 1. Número y frecuencia de células testiculares observadas en dos grupos etarios de perros en muestras obtenidas mediante punción y aspiración con aguja fina

\begin{tabular}{lcccc}
\hline \multirow{2}{*}{ Tipo celular } & \multicolumn{2}{c}{$\begin{array}{c}\text { Adultos (2-6 años) } \\
(\mathrm{n}=10)\end{array}$} & \multicolumn{2}{c}{$\begin{array}{c}\text { Geriátricos }(>8 \text { años }) \\
(\mathrm{n}=10)\end{array}$} \\
\cline { 2 - 5 } & $\mathrm{n}$ & $\%$ & $\mathrm{n}$ & $\%$ \\
\hline Células rotas & 5,293 & 5.8 & 2,728 & 5.0 \\
Células de Sertoli & 9,370 & 10.3 & 6,805 & 12.3 \\
Células de Leydig & 1,143 & 1.3 & 953 & 1.7 \\
Células germinales & $52,545^{\mathrm{a}}$ & 57.5 & $28,672^{\mathrm{b}}$ & 51.9 \\
Espermatozoides & $23,020^{\mathrm{a}}$ & 25.2 & $15,771^{\mathrm{b}}$ & 28.6 \\
Células anormales & $40^{\mathrm{a}}$ & 0.04 & $293^{\mathrm{b}}$ & 0.5 \\
Células inflamatorias & 0 & 0 & 0 & 0 \\
\hline Total & $91,411^{\mathrm{a}}$ & 100.0 & $55,222^{\mathrm{b}}$ & 100.0 \\
\hline
\end{tabular}

${ }^{a, b}$ Superíndices diferentes dentro de filas indican diferencias significativas $(p<0.05)$
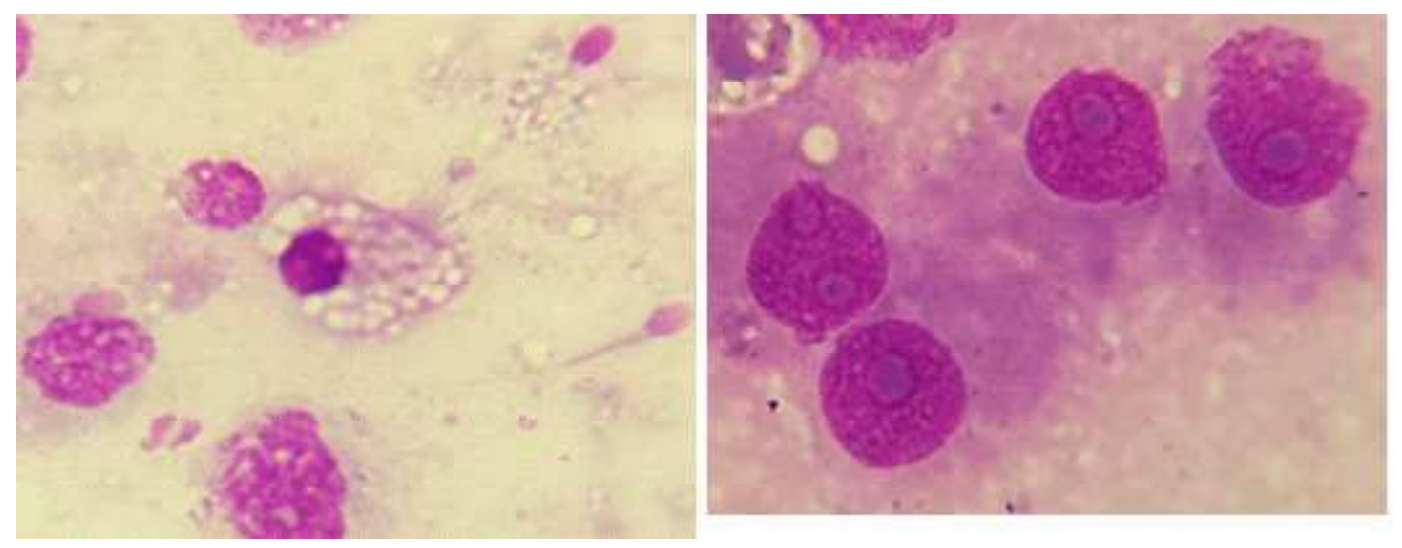

Figura 2. Células testiculares colectadas mediante aspiración con aguja fina. A. Célula de Leydig en el centro de la imagen. B. Tres células de Sertoli con nucléolos grandes y una célula de Sertoli con dos nucléolos pequeños. May-Grünwald Giemsa, 1000x

de Leydig; además, muchas veces se apreciaban sin su citoplasma y solo como núcleos desnudos. Su núcleo también era redondo y en la cromatina se observaba un patrón finamente punteado.

No se pudo encontrar ni identificar con claridad las espermatogonias en ambos grupos de perros, lo cual se podría explicar por su escasez relativa respecto de otras células más diferenciadas, como los espermatocitos y espermátidas (Santos et al., 2010). Los espermatocitos primarios se identificaron como las células más grandes (Fig. 1B). Son de forma redonda, al igual que el núcleo. La coloración del núcleo siempre fue muy basófila. Todos los perros, con excepción de uno, presentaron células con un único nucléolo, también redondo. En las células de Sertoli que conservaron su citoplasma intac- 
to, este era abundante, claro, irregular y con pequeñas microvacuolas. Estas observaciones concuerdan con publicaciones previas (Dahlbom et al., 1997; Santos et al., 2010; Gouletsou et al., 2011).

\section{Perros Adultos y Geriátricos}

En la evaluación clínica, el 100 y $60 \%$ de los perros adultos y geriátricos, respectivamente, presentaron consistencia testicular normal. En los geriátricos, tres perros tenían testículos flácidos y uno lo tenía duro, sin apreciarse alteraciones ecográficas importantes. Los valores absolutos y relativos en los recuentos celulares, considerando la categoría celular y los grupos etarios, se presentan en el Cuadro 1.

El recuento total de células, considerando ambos grupos etarios, fue 146633 células, correspondiendo el $62.3 \%$ al grupo de perros adultos y el $37.7 \%$ restante al grupo de perros geriátricos $(\mathrm{p}<0.05$; Cuadro 1$) . \mathrm{La}$ mayor diferencia entre grupos se registró en la categoría de células germinales y espermatozoides donde el 64.7 y $59.3 \%$ de estas células fueron registradas en perros adultos, así como de células anormales donde el $88 \%$ se observó en perros geriátricos ( $\mathrm{p}<0.05$; Cuadro 1).

Más del 50\% de las células en cada grupo estuvo representado por células germinales, seguido por los espermatozoides, que representan la cuarta parte del total de células. La predominancia de estos grupos celulares se puede explicar por el orden creciente de producción en los túbulos seminíferos desde espermatogonias, espermatocitos, espermátidas (tempranas y tardías) hasta espermatozoides (Santos et al., 2010).

En perros geriátricos se observó con frecuencia en las espermátidas tempranas una irregularidad de los bordes del núcleo y la cromatina menos compacta y organizada que en los perros adultos. Estas observaciones son concordantes con las alteraciones en los cambios morfológicos durante la espermiogénesis que se pueden presentar en perros viejos (McEntee, 1990; Nelson y Couto, 2000).

Las células de Leydig fueron las de menor representación (después de las células anormales). Su bajo número es concordante con la menor superficie que ocupa el espacio intersticial (rodeando a los grandes túbulos seminíferos) dentro del tejido testicular (Santos et al., 2010). La característica más distintiva del citoplasma de las células de Leydig fue la presencia de múltiples vacuolas que ocupan prácticamente toda la superficie citoplasmática (Figura 2A). No se encontraron diferencias en este tipo celular entre perros adultos y geriátricos. Por otro lado, en las células de Sertoli de un perro geriátrico se registraron nucléolos dobles, muy prominentes y de mayor tamaño (Fig. 2B), hallazgo que podría corresponder al inicio de un tumor de células de Sertoli, ya que estas células poseen un único nucléolo (Santos et al., 2010), en tanto que en el tumor de células de Sertoli se presentan hasta tres nucléolos grandes y prominentes (Masserdotti et al., 2005; Raskin y Meyer, 2010).

El alto número de células rotas registrado en ambos grupos es concordante con lo señalado por Raskin y Meyer (2010), quienes explican que, en general, la técnica de aspirado con presión negativa lisa una alta cantidad de células.

Estos resultados contribuirían a la comprensión de la disminución de la función reproductiva en los perros de mayor edad, la cual podría ser el resultado de varias condiciones como alteraciones en el control hormonal de la función testicular (Lopate, 2010), el desarrollo de procesos neoplásicos testiculares (Masserdotti et al., 2005; Raskin y Meyer, 2010), la degeneración testicular (McEntee, 1990) y, más específicamente, las alteraciones en la espermatogénesis (Masserdotti et al., 2005; Romagnoli et al., 2009; Lopate, 2010). 


\section{Conclusiones}

- Los recuentos celulares totales de muestras testiculares obtenidas por punción y aspiración con aguja fina indicaron diferencias significativas entre perros adultos y geriátricos.

- Los perros adultos presentaron mayor número de células germinales y espermatozoides.

- Los perros geriátricos presentaron mayor número de células anormales.

\section{Literatura Citada}

1. Dhalbom M, Mäkinen A, Suominen J. 1997. Testicular fine needle aspiration cytology as a diagnostic tool in dog infertility. J Small Anim Pract 38: 506512. doi: 10.1111/j.1748-5827.1997. tb03307.x

2. Gouletsou P, Galatos A, Leontides L, Sideri A. 2011. Impact of fine- or largeneedle aspiration on canine testes: clinical, in vivo ultrasonographic and seminological assessment. Reprod Dom Anim 46: 712-719. doi: 10.1111/j.14390531.2010.01734.x

3. James R, Heywood R, Fowler D. 1979. Serial percutaneus testicular biopsy in the Beagle dog. J Small Anim Pract 20: 219-228. doi: 10.1111/j.17485827.1979.tb06709.x

4. Johnston S, Kustritz M, Olson P. 2001. Canine and feline theriogenology. Philadelphia, USA: WB Saunders. 592 p.
5. Lopate C. 2010. Clinical approach to conditions of the male. In: England G Von Heimendahl A (eds). BSAVA Manual of canine and feline reproduction and neonatology. $2^{\text {nd }}$ ed. UK. BSAVA. p 191-196.

6. McEntee K. 1990. Reproductive pathology of domestic mammals. California, USA: Academic Press. 401 p.

7. Masserdotti C, Bonfanti, $U$, De Lorenzi, D, Tranquillo M, Zanetti $O$. 2005. Cytologic features of testicular tumors in dogs. J Vet Med A Physiol Pathol Clin Med. 52: 339-346.

8. Nelson R, Couto C. 2000. Medicina interna de animales pequeños. $2^{a}$ ed. Buenos Aires, Argentina: Inter-Médica. 1504p.

9. Raskin R, Meyer D. 2010. Canine and feline cytology: A color atlas and interpretation guide. $2^{\text {nd }}$ ed. St. Louis: Saunders. $450 \mathrm{p}$.

10. Root Kustritz M. 2006. Collection of tissue and culture samples of the canine reproductive tract. Theriogenology 66: 567-574. doi: 10.1016/ j.theriogenology.2006.05.003

11. Romagnoli S, Bonaccini P, Stelletta C, Garolla A, Menegazzo M, Foresta $C$, Mollo A, et al.. 2009. Clinical use of testicular fine needle aspiration cytology in oligozoospermic and azoospermic dogs. Reprod Dom Anim 44: 329-333. doi: 10.1111/j.1439-0531.2009.01439.x

12. Santos M, Marcos R, Caniatii M. 2010. Cytologyc study of normal canine testis. Theriogenology 73: 208-214. doi: 10.1016/j.theriogenology.2009.07.030

13. Suárez M. 2012. Interaprendizaje de probabilidades y estadística inferencial con Excel, Winstats y Graph. Ecuador: M \& V Ibarra. 226 p. 